\title{
Contribuições de uma Intervenção Psicoeducativa para o Enfrentamento do HIV durante a Gestação ${ }^{1}$
}

\author{
Tonantzin Ribeiro Gonçalves ${ }^{2}$ \\ Universidade do Vale do Rio dos Sinos \\ Cesar Augusto Piccinini \\ Universidade Federal do Rio Grande do Sul
}

\begin{abstract}
RESUMO - O estudo investigou as contribuições de uma intervenção psicoeducativa para o enfrentamento da doença entre gestantes vivendo com HIV. Participaram quatro mães com idades entre 29 e 37 anos, sendo que duas souberam da infecção na gestação. Trata-se de estudos de casos longitudinal envolvendo avaliações antes, durante, depois da intervenção e aos três meses de vida do filho/a. Os achados revelaram que a notícia do HIV durante a gestação se associou a grande risco psicológico, pois envolvia imenso esforço de adaptação e sobrecarga emocional potencializadas pelo risco de transmissão do vírus ao filho. A intervenção apresentou contribuições positivas para o enfrentamento da doença e o bem-estar emocional das mães. Discutese a necessidade de ampliar o apoio psicológico dos serviços de saúde a essas mulheres.
\end{abstract}

Palavras-chave: gestação, HIV/aids, intervenção, enfrentamento

\section{Contributions of a Psychoeducational Intervention to Cope with HIV during Pregnancy}

\begin{abstract}
The study investigated the contributions of a brief psychoeducational intervention during pregnancy to cope with HIV among women living with HIV. Participants were four mothers, 29 to 37 years old, two of them diagnosed during their current antenatal exams. A collective study-case design was used to examine mother's accounts before, after and during intervention sessions, as well as an assessment in the third month of the baby. Results revealed HIV diagnosis during pregnancy represented a situation of psychological risk, since it required a huge adaptation effort and an emotional burden caused by the possibility to transmit the disease to the child. In this context, the psychoeducational intervention showed positive contributions confronting HIV and to the emotional well being of the mothers. The need for appropriate psychological support to all pregnant women living with HIV is discussed.
\end{abstract}

Keywords: pregnancy, HIV/aids, intervention, coping

Nas últimas duas décadas houve grande aumento da transmissão heterossexual do HIV no Brasil e, consequentemente, na taxa de incidência entre mulheres (Brasil/MS, 2011). Grande parte dessas mulheres está em idade reprodutiva e muitas delas tornam-se mães, gerando preocupação com a transmissão materno-infantil (TMI) do vírus. Assim, o Ministério da Saúde tem fortalecido o combate à TMI, com recomendações profiláticas que envolvem a atenção primária, a rede hospitalar e os serviços especializados em HIV/aids. Esses esforços têm diminuído as taxas de TMI, especialmente no Sul do país (Souza Jr, Szwarcwald, Barbosa Jr, Carvalho, \& Castilho, 2004).

A maternidade, por si só, se constitui em um processo psicológico complexo para qualquer mulher (Stern, 1997) sendo que o HIV/aids acrescenta sobrecargas sociais e psicológicas. A mãe vivendo com HIV precisa lidar com o próprio diagnóstico, em muitos casos, revelado pela gestação, ao mesmo tempo em que realiza procedimentos para evitar a transmissão para o bebê. Esse processo é acompanhado por sentimentos de culpa e medo de infecção no filho, sofrimento psicológico e estigma (Faria \& Piccinini, 2010; Gonçalves \& Piccinini, 2008; Kwalombota, 2002).

Com o advento dos antirretrovirais (ARVs), em 1996, muitas intervenções psicológicas foram desenvolvidas, evidenciando atenção crescente às questões psicossociais da epidemia, como o bem-estar e qualidade de vida dos indivíduos (Faria, Gonçalves, Carvalho, Moskovics, \& Piccinini, 2012). Contudo, a maioria dessas intervenções tem sido realizada em países desenvolvidos e segue focada em grupos populacionais (i.e., homens que fazem sexo com homens), havendo poucas publicações brasileiras e, menos ainda, com gestantes vivendo com HIV (Faria et al., 2012; Gonçalves, 2011). No Brasil, uma intervenção utilizada como estratégia no combate à epidemia é a técnica de aconselhamento. O Ministério da Saúde recomenda o aconselhamento no atendimento aos pacientes vivendo com HIV, principalmente em situações de testagem de HIV e outras DSTs, o que inclui a realização do exame entre gestantes no pré-natal (Brasil/MS, 1999, 2005). Mesmo que o aconselhamento seja considerado como parte do tratamento

1 Apoio: $\mathrm{CNPq}$

2 Endereço para correspondência: Av. Unisinos, 950, São Leopoldo, Rio Grande do Sul, Brasil. CEP: 93022-000. E-mail: tonanrib@yahoo.com.br 
em HIV, percebe-se uma menor ênfase nos estudos empíricos nas necessidades psicológicas dessa população (Carvalho, Faria, Gonçalves, Moskovics, \& Piccinini, 2009; Gerbert et al., 2006). Nesse sentido, pesquisadores (Medley, GarciaMoreno, McGill, \& Maman, 2004) salientam a necessidade de que o aconselhamento no contexto de pré-natal focalize as decisões que as mulheres vivendo com HIV precisam tomar nesse momento.

Considerando essas demandas, foi desenvolvida uma proposta de intervenção psicoeducativa direcionada ao contexto de pré-natal de mulheres vivendo com HIV, com base nos pressupostos do aconselhamento em HIV (Brasil/ MS, 1999, 2005). Essa intervenção objetiva auxiliar na adesão à profilaxia da TMI e ao tratamento para HIV, em situações de sigilo/revelação do diagnóstico, além de oferecer apoio psicológico, promovendo a qualidade de vida e as estratégias de enfrentamento. Um estudo quantitativo incluindo apenas gestantes que já sabiam do HIV antes de engravidarem (Carvalho, 2009) mostrou contribuições positivas dessa intervenção para o enfrentamento do HIV e para a qualidade de vida das mães. O presente estudo examinou qualitativamente as contribuições do Programa de Intervenção Psicoeducativa para Gestantes vivendo com HIV/Aids (PIP-Gestantes) para o enfrentamento da doença entre mães com diagnóstico de HIV anterior ou durante a gestação.

\section{Método}

\section{Participantes}

Participaram quatro gestantes vivendo com HIV, duas primíparas e duas multíparas, sendo que duas já sabiam do diagnóstico antes de engravidarem e duas souberam durante o pré-natal. Todas eram casadas, de níveis socioeconômicos médio a baixo e foram recrutadas em um serviço especializado em HIV de um hospital da rede pública de saúde de Porto Alegre onde faziam seu tratamento. As gestantes foram selecionadas no projeto Aspectos psicossociais, adesão ao tratamento e saúde da mulher no contexto do HIV/AIDS: contribuições de um programa de intervenção da gestação ao segundo ano de vida do bebê - PSICAIDS (Piccinini et al., 2005). A seleção dos casos priorizou ainda a heterogeneidade quanto ao contexto da gestação (i.e., primípara ou multípara) e do diagnóstico de HIV (antes ou durante aquela gestação).

\section{Delineamento, procedimentos e instrumentos}

Foram realizados estudos de casos (Stake, 1994) visando investigar as contribuições do PIP-Gestantes para o enfrentamento do diagnóstico de HIV em situação de gestação. Para tanto, foram analisadas as entrevistas de avaliação pré e pós-intervenção, os relatos das mães ao longo da intervenção e a avaliação aos três meses de vida do bebê. O recrutamento e coleta de dados seguiram as etapas descritas no PSICAIDS e detalhados em Gonçalves (2011). Destacam- se aqui apenas os instrumentos utilizados no presente estudo, com dados da gestação e dos 3 meses do bebê.

$\mathrm{Na}$ Fase I, as mães foram contatadas no pré-natal especializado em HIV. Aquelas que concordaram, preencheram a Entrevista de Dados Sociodemográficos da Família, utilizada para identificação dos critérios de inclusão no estudo. Depois disto, as mães assinaram o Termo de Consentimento Livre e Esclarecido e, ao concluírem 24 semanas de gestação, respondiam a Entrevista sobre a Gestação em Situação de Infecção pelo HIV que investigou aspectos relacionados à gestação, às relações familiares, ao diagnóstico e à profilaxia da TMI.

Após a avaliação inicial, as mães participaram da intervenção PIP-Gestantes, que foi construída para o projeto PSICAIDS e tinha como objetivos gerais auxiliar na adesão à profilaxia da TMI e ao tratamento para HIV, no manejo do sigilo/revelação e oferecer apoio psicológico, promovendo o enfrentamento da doença. A intervenção consistia de cinco encontros individuais com duração aproximada de uma hora, conduzidos com base nas recomendações do Ministério da Saúde (Brasil/MS, 1999, 2005) sobre aconselhamento em HIV. Cada encontro baseava-se em temas específicos: 1) Expectativas e planejamento da intervenção; 2) Aspectos físicos e emocionais da gestação e da infecção pelo HIV; 3 ) Parto, puerpério e desenvolvimento inicial do bebê; 4) Família e apoio social; e 5) Convivendo com o tratamento para HIV. As temáticas eram abordadas de modo personalizado, favorecendo a expressão de sentimentos, sendo os aspectos informativos introduzidos a partir dos conhecimentos prévios e dúvidas da participante. Os pais dos bebês foram convidados a participar. O PIP-Gestantes foi conduzido por psicólogas experientes na área do HIV, previamente capacitadas em aconselhamento e supervisionadas ao longo da intervenção. Outros detalhes e o manual da intervenção podem ser consultados em Gonçalves(2011). Após a intervenção, as mães respondiam à Entrevista de Avaliação da Intervenção que investigava suas percepções sobre a participação na mesma.

Na Fase II do estudo, aos 3 meses do bebê, realizava-se a Entrevista sobre a Maternidade em Situação de Infecção pelo HIV e a Entrevista sobre o Desenvolvimento do Bebê e a Interação Mãe-Bebê no Contexto da Infecção Materna pelo HIV. Todas as entrevistas e sessões de atendimento dos casos do presente estudo foram conduzidas pela primeira autora, com exceção da Entrevista sobre a Avaliação da Intervenção, realizada por outra pesquisadora do projeto. As entrevistas e as sessões da intervenção foram gravadas em áudio e transcritas. O projeto PSICAIDS, do qual o presente estudo faz parte, foi aprovado pelos comitês de ética da Universidade Federal do Rio Grande do Sul (Proc. 2005508) e do Grupo Hospitalar Conceição (Proc. 06/06).

\section{Resultados e Discussão}

A partir da leitura exaustiva do material transcrito e com base nos temas abordados pelo PIP-Gestantes e na literatura (Carvalho et al., 2009; Gonçalves \& Piccinini, 2008; Sanders, 2008; Wilson, 2007), realizou-se análise de conteúdo qualitativa (Joffe \& Yardley, 2004; Laville \& Dione, 
1999). As análises contemplaram a categoria: Lidando com o diagnóstico de HIV, que compreendeu os relatos das mães sobre experiências, sentimentos e estratégias frente ao HIV associadas ao diagnóstico, estigma, preconceito e sigilo quanto à doença. Incluíram-se verbalizações sobre a notícia da infecção, suas repercussões íntimas, familiares e sociais, além da forma como as mães lidavam com o diagnóstico e o tratamento. Quanto à maternidade, incluíram-se temores e atitudes frente à revelação do HIV no parto e pós-parto e pela não-amamentação no seio. Foram investigadas eventuais mudanças nos relatos que indicassem contribuições da intervenção para o enfrentamento da doença. A análise foi conduzida com auxílio do software NVivo 2.

A seguir, será apresentada uma breve caracterização de cada caso, ilustrando com relatos das mães. A apresentação dos resultados será feita na primeira pessoa do singular, considerando-se a proximidade e envolvimento da primeira autora com as participantes.

\section{Caso Daiana e Cássio}

Daiana, funcionária pública, e Cássio, profissional autônomo, estavam casados há 11 anos e esperavam seu primeiro filho. O marido teve o diagnóstico de HIV quatro anos antes, durante uma internação por pneumonia. O exame de Daiana também foi positivo, mas ela iniciou o tratamento com ARVs um ano e meio depois. Ambos admitiam situações de sexo desprotegido antes de se conhecerem e, por isso, não se culpavam mutuamente. Daiana estava muito preocupada, pois engravidou tomando um ARV não recomendado para gestantes pelo potencial de causar malformações na criança. O remédio foi suspenso nas primeiras semanas da gravidez e o bebê não apresentou alterações morfológicas nos exames de ecografia. Daiana ficou insatisfeita por não ter sido alertada, pois comunicara ao médico anterior sua intenção de engravidar. $\mathrm{O}$ casal planejara a gravidez e, sem orientações específicas, pararam de usar o preservativo e esperaram a concepção.

O casal mantinha uma relação distante com suas famílias de origem e decidiram não revelar-lhes o diagnóstico de HIV. Todavia, por ocasião do diagnóstico de Cássio, três familiares dele souberam da doença inadvertidamente e se comprometeram a não revelá-la aos demais. Daiana e o marido serviam, um para o outro, como fontes primárias de apoio, sendo a ajuda dos profissionais de saúde muito importante. O casal motivou-se a participar da intervenção, pois Daiana se preocupava com o risco de infecção da filha, tinha dúvidas sobre a profilaxia e com o sigilo.

$\mathrm{Na}$ avaliação pré-intervenção ficou evidente que Daiana estava emocionalmente adaptada ao diagnóstico de HIV, demonstrando recursos internos para lidar com a notícia desde os primeiros momentos. No âmbito social, o casal optou pelo sigilo sobre a infecção pelo medo do preconceito. O casal temia que essa revelação pudesse causar sofrimento, especialmente para os seus pais, considerados pessoas emocionalmente frágeis. Daiana revelou que ser tratada como "coitadinha" lhe era insuportável, deixando transparecer que essa estratégia também servia a algum grau de negação da doença: "E para nós até é melhor porque acho que a pior coisa numa situação dessas é começar a ser tratado como coitadinho e a minha mãe já me trata como coitadinha sem eu ter nada" [grifo do autor]. A gravidez fora bem recebida pelos familiares, mas Daiana temia que o HIV fosse revelado pela não-amamentação no seio, algo que a família valorizava muito.

No tocante ao enfrentamento do HIV, a participação na intervenção não parece ter provocado mudanças substanciais, pois Daiana já mostrava bom ajustamento, tendo uma boa adesão ao tratamento e atitudes positivas frente à doença. Ela parecia significar a doença em termos de sua trajetória pessoal e familiar, tomando essa responsabilidade para si, como mostra esse relato: "Eu sempre pensei que um motivo me levou a adquirir isso. Pode ter sido a minha conduta. $O$ motivo está dentro de mim, fui eu que busquei isso". Mesmo assim, a intervenção possibilitou um espaço de reflexão e revisão de delicados aspectos da convivência com o vírus como o enfrentamento do estigma, do preconceito e do sigilo. Este último ponto consistia na principal demanda do casal, já que Daiana tinha uma prima que era profissional de saúde, como foi discutido no primeiro encontro: "O que me preocupa agora é a hora do parto, se vai ter mesmo sigilo, se alguém vai descobrir por causa de algum procedimento que vai ser feito. (...) Eu não posso nem pensar. Se eles descobrirem, eu prefiro sumir". Ao longo da intervenção, Daiana revisou seus sentimentos frente ao HIV, discutindo experiências que a levavam a manter o sigilo. No segundo encontro, por exemplo, ela refletiu sobre como lidava com a doença, o que envolvia um movimento, ora de reconhecer sua gravidade, ora de evitação: "Eu tenho uma vida normal, fora ter que tomar remédio, mas os outros tratam as pessoas com o vírus como doente grave. Então quer dizer que é grave o que eu tenho, não adianta querer 'tapiar"'. Era como se a gestação a obrigasse a diminuir o ritmo e a retomar seus sentimentos diante da doença.

O nascimento da filha trazia novos desafios para a preservação do sigilo e o casal tinha dúvidas como, por exemplo, o que diriam sobre a não-amamentação e o que fariam para evitar que a família suspeitasse de algo durante a internação. Sobre isso, o casal debateu sobre qual seria a melhor justificativa para a família e Daiana antecipou suas estratégias, como se percebe a seguir:

Eu pensei em dizer que eu não tenho leite. Porque esse negócio que a doutora disse: "Ah, que tu podes inventar que teve hepatite quando tu eras pequena”. Mas a minha mãe sabe que eu não tive. [...] Eu acho que vai ser isso ai que nós vamos inventar. [...] Mas também eu não vou ficar falando muito disso, não dá para dar muito espaço.

A presença de profissionais de saúde na família trazia dificuldades para o sigilo e o casal não parecia suficientemente atento. Daiana relutava em aceitar que alguém pudesse descobrir a doença e buscava soluções, tais como proibir visitas após o parto.

A participação de Daiana e Cássio na intervenção oportunizou antever situações que podiam revelar a infecção pelo HIV para suas famílias e foram debatidas estratégias para o sigilo adaptadas às suas necessidades e a situação da profilaxia da TMI no parto e pós-parto. Com a presença do 
marido no terceiro encontro, discutimos o que dificultaria a manutenção do sigilo e o casal fez várias perguntas sobre a conduta da equipe do hospital, sendo que se buscou traçar estratégias para minimizar o risco da revelação. $\mathrm{O}$ marido contou sobre uma revelação acidental do diagnóstico que Daiana não soube e que sublinhava a fragilidade do sigilo no ambiente hospitalar. Isso parece ter lhe ajudado a considerar alternativas para lidar com o sigilo:

Cássio: Também tem o seguinte. Uma coisa que eu até já tinha falado com a Daiana, que ela tem um pavor se isso acontecer, da prima dela saber. [...] Eu acho que no final até é mais fácil, se isso se tornar inevitável, pegar, puxar ela num cantinho lá e falar: "Oh, seguinte, assim, assim" [Risos].

Terapeuta: É legal a gente pensar nisso antes porque, o que acontece? Lá na hora tu vais estar frágil, tu vais ter acabado de ter ganhado teu bebê. [...] É uma coisa para gente pensar em estratégias para evitar que isso aconteça na frente de outras pessoas que de repente vocês não querem revelar. [...]

Cássio: Eu tinha pensado nessa hipótese no início. [...] De usar ela para lançar uma cortina de fumaça.

O casal foi incentivado a conversar com a equipe médica para que a sua opção de não revelar a doença para a família fosse respeitada. Eles discutiram o assunto com a obstetra e decidiram só revelar o HIV para a prima, caso fosse inevitável e que estariam prevenidos para isso. A esse respeito, discutiu-se como agiriam caso ela descobrisse a doença e eles decidiram ir sozinhos para o hospital para o parto, evitando que o diagnóstico ficasse mais exposto à família. A busca de apoio técnico e pela racionalidade para lidar com a doença ficou evidente ao longo da intervenção com esse casal. Isso parecia favorecer para eles a aceitação da doença e do tratamento como responsabilidades suas, como o pai referiu no quarto encontro:

A ideia é [...] tu não dá uma desculpa. Porque tu fica irresponsável pelos teus atos. Eu acho que esse foi o motivo de encarar melhor o fato do HIV porque a gente sabe o único e exclusivo culpado.

Essas reflexões e decisões foram sendo explicitadas pelo casal e parecem ter propiciado maior segurança diante das perguntas da família e de outros sobre os remédios e a nãoamamentação, como Daiana explicitou:

Durante os encontros eu fui conversando com a minha mãe, fui abrindo a cabeça dela, aplicando algumas coisas que a gente estava conversando aqui. Agora ela já está domada. Porque ela estava querendo trazer todo mundo para o hospital. Daí eu já resolvi que vai vir só eu e o Cássio e depois a gente vai chamar os outros. Na hora da chegada aqui pode dar confusão.

Ademais, eles puderam antecipar suas próprias reações e atitudes diante de uma possível descoberta da doença pela prima de Daiana o que, de fato, ocorreu. Lamentavelmente não houve a preservação do sigilo desejado pelo casal, o que poderia ter implicado em mais dificuldades se o fato não tivesse sido antevisto, o que permitiu a eles conversar com a prima e ter seu apoio para manter o segredo.

\section{Caso Regina}

Regina, dona de casa, estava grávida de seu quarto filho e recebera o diagnóstico de HIV seis anos antes, quando solicitou um exame anti-HIV, pois planejava ter um menino. $\mathrm{Na}$ época, ela já suspeitava que o marido tivesse a doença, pois ele fora usuário de drogas e apresentava suores e febre repentina. $\mathrm{O}$ casal passou por um período difícil e o marido logo iniciou os ARVs. Um ano depois e realizando a profilaxia da TMI, ela teve sua terceira filha, não infectada pelo HIV, assim como as duas primeiras. Apesar de não planejada, a atual gravidez foi festejada, pois teria, enfim, um menino. A gestação ocorreu logo depois de Regina reconciliar-se com o marido, após quase um ano de separação.

O casal era oriundo do interior do estado, mas só ela tinha contato com a família de origem, que morava na capital. Toda a família de Regina, exceto o seu pai, sabia sobre o HIV e a apoiavam, mesmo não falando abertamente no assunto. Sua maior preocupação era ter engravidado justamente quando abandonara os ARVs. Ela teve fortes reações ao novo remédio (Kaletra) e o médico decidiu retornar ao antigo esquema. O tratamento teve sucesso e sua carga viral voltou a níveis indetectáveis o que, todavia, não tranquilizou Regina que se sentia muito insegura quanto à TMI e à doença. Ademais, ela deixou o trabalho de sacoleira pelo risco de aborto.

$\mathrm{Na}$ avaliação pré-intervenção, Regina demonstrou ter posturas delineadas diante da doença como, por exemplo, sobre a necessidade de proteger-se do estigma, preservando o sigilo entre amigos. Se, por um lado, seus familiares não manifestavam discriminação, Regina percebia que outras pessoas tinham atitudes preconceituosas, como apareceu no quarto encontro: "Tem pessoas que acham que se um mosquito me morder, picar aqui, depois for picar ai, também tão contaminadas. Já vi pessoas falando assim. Tem pessoas que acham que no chimarrão, tomando junto, pega. Eu só fico analisando." Ela não parecia ter dificuldades em manter o sigilo, precavendo-se de situações potencialmente reveladoras e mostrando desenvoltura quando precisava justificar os remédios e a não-amamentação no seio:

Eu vou ter que lidar tudo desdobrado como lidei com a Elisa, dizer que eu não tô amamentando porque não tem mais leite. Até mesmo tem pessoa mais idosa que diz: "Ah, toma isso que vem, toma mate doce com leite que vem". Eu dizia: "Eu já tentei de tudo, não vem, ela tá com fome, vou tacar mamadeira."

Seus filhos e suas crenças religiosas eram o cerne de suas estratégias para lidar com o HIV, fornecendo-lhe sentido e motivação para seguir em frente. Contudo, como mostra o relato a seguir, apesar de essa atitude lhe fazer sentir-se mais forte, permanecia uma sensação de fragilidade e grande insegurança quanto ao futuro: "Tu te torna uma guerreira. Fica forte. É uma luta, fica lutando para sobreviver, porque nunca sabe até onde tu vai, até onde tu vai ter proveito dos teus filhos, da tua familia. [...] Tu fica naquela dependência dos remédios." Seus relatos revelaram que, mesmo após seis anos desde a notícia da infecção e de ter tido uma filha na presença do HIV, alguns aspectos ainda eram difíceis, sendo que a frequência no hospital durante o pré-natal e o convívio com pacientes debilitados, revivia seus temores de morte: 
Tu vê pessoas que estão naquela fase meia terminal, parece que não se alimenta, não come, tão mal, perdendo cabelo. E tu olha: "Bah, será que eu vou ficar assim? Será que vou chegar a ficar até que idade? Será que quando ele [o filho] chegar aos 14 anos eu vou tá viva?" Ai quando tu sai daqui [hospital], tu já sai numa tristeza.

Destacou-se também a dificuldade em aderir aos ARVs, o que gerou insegurança sobre sua saúde na gestação. Para ela, a separação conjugal lhe trouxera a depressão e contribuiu para que desistisse dos ARVs. Todavia, ao expor seus sentimentos quanto à doença ao longo da intervenção, atitudes mais positivas passaram a prevalecer nos seus relatos. Mesmo sem revelar o HIV em sua comunidade religiosa, seu trabalho junto a enfermos parecia lhe ajudar a lidar com a doença:

Tu chega lá se depara com um quadro: A pessoa na cama, enfermo, magro. [...] Ai tu começa a entrar, é um tratamento, primeiro tem que lidar com a pessoa, depois tu vai dando um jeito na casa. Quando tu vê a pessoa já tá levantando da cama, é um processo. Já começou a ir na igreja, devagar, meia fraquinha mas tá indo. Quando tu vê que ela tá tendo vitória para ti já é gratificante, nossa! Deus fez ali, Deus vai me ajudar e me dar muito mais.

Embora a intervenção não tenha abordado profundamente aspectos subjetivos da adaptação ao diagnóstico, esta parece ter ajudado Regina a restabelecer certo senso de controle que fora perdido devido ao abandono do tratamento, como evidencia seu relato na avaliação pós-intervenção: " $E u$ cheguei aqui até sem medicação, meio ano que eu tava sem medicação, eu tive uma separação, tava meio perdidona. [...] Fez mal aqueles primeiros remédios que eu tomei. [...] Foi uma coisa [intervenção] que chegou na hora certa." Nesse sentido, o apoio dos familiares e do marido, além de sua experiência anterior de gravidez na presença do HIV, contribuiu para que ela readquirisse a segurança quanto à sua saúde e ao futuro da família.

\section{Caso Laura}

Ao conhecê-la, Laura estava afastada do trabalho de comerciária pela ameaça de aborto que sofreu pouco antes de receber o diagnóstico de HIV, no quarto mês de gestação. $\mathrm{Na}$ época, o marido, cinco anos mais moço, fez o exame anti-HIV que resultou negativo. O casal planejou a gestação do primeiro filho de ambos, a qual ocorreu logo depois que passaram a morar juntos na casa dos sogros de Laura. Ela foi profissional do sexo e usuária de drogas e estava há mais de um ano sem contato com essas atividades, desde que começou a namorar o atual marido.

Além do marido, sua mãe, a irmã mais velha e a avó materna, essa última também HIV+, sabiam da sua doença. Laura sentia-se fortemente perturbada pelo diagnóstico, preocupava-se muito com o risco de TMI e achava que a doença era um castigo por erros no passado. Devido ao abalo emocional, Laura foi encaminhada e aguardava atendimento psicológico na rede pública, sendo que, por esse motivo, entendemos que ela poderia se beneficiar da intervenção em aspectos pontuais.

$\mathrm{Na}$ avaliação pré-intervenção foi visível o sofrimento de Laura diante do diagnóstico de HIV, sendo-lhe muito difícil assimilar a notícia devido à permanente sensação de falta de controle. Percebeu-se que ela tentava denegar o problema seja tentando de modo deliberado esquecê-lo, ou elencando outros motivos que explicassem sua intensa perturbação emocional. Ela parecia sentir que a doença era autoevidente e que pessoas próximas poderiam descobri-la a qualquer momento, o que desafiava sua tentativa de negá-la e exacerbava o medo da discriminação. "Tá sendo bem difícil pra mim. A minha cabeça tá bem complicada. [...] Parece que as pessoas tão me olhando e tão vendo [HIV]. [...] Eu vou ter que voltar a trabalhar agora e fica todo mundo me perguntando." Durante a avaliação inicial, Laura desviou-se do assunto do diagnóstico por várias vezes, tentando encobrir a angústia que isso lhe trazia ou dissociando seus sintomas emocionais dessa notícia. Busquei respeitar suas negativas mesmo pontuando o nexo entre o diagnóstico e seu estado emocional e, aos poucos, Laura foi revelando toda a carga de culpa que a descoberta do HIV lhe trazia. Este envolvia não apenas a possibilidade de infectar o filho, mas de ter infectado outros parceiros no passado. O diagnóstico lembrava-lhe momentos difíceis de sua vida associados a conflitos com os pais, ao uso de drogas e à prostituição, que a recriminavam ainda mais: "Eu tive mais relacionamentos. E eu ficava pensando: "Meu Deus para quem que será? Para quantas pessoas passei isso?" [...] Que vergonha, que feio, isso ai é uma coisa que não tem explicação."

Foi possível perceber que a reação dela ao diagnóstico só não teve consequências mais dramáticas em função do apoio do marido e de familiares que a acolheram e buscaram mostrar-lhe uma perspectiva mais positiva quanto à doença. Por outro lado, algumas reações de ajuda da família acabavam por reforçar sua negação da doença, dificultando que a dor, a culpa e o medo fossem expressos:

\footnotetext{
Ele [marido] veio conversar comigo: "Ah, eu te amo. Nós vamos criar nosso filho". [...] "Ninguém vai morrer disso". E começou a falar pra mim parar de chorar, que as coisas não eram assim, começou a me apoiar dali em diante. Ele disse: "Não fica pensando nessas coisas porque isso aí, se pensar, vai ser pior. Não bota isso na cabeça. Vamos esquecer isso e vamos fazer de conta que... Toma os remédios e faz de conta que tu não tem nada."
}

Assim, a dificuldade em lidar com a doença não era apenas dela, mas também da família e do marido. Ele desaprovava que Laura falasse da doença para outros familiares como o pai e irmãos dela, que souberam através da mãe, mas com quem ela não comentava o assunto. Somava-se a isso o temor de que a família do marido manifestasse preconceito ao saber do HIV, pois já haviam presenciado a reação deles a pessoas vivendo com aids, como debatido no quarto encontro: "A irmã dele tá todo o dia falando que o fulano morreu de aids. Eu falo: 'Ninguém morre de aids.' 'Morre sim!' E eu: 'Não, não morre'. Tem gente ignorante ainda, fazer o quê? [...] Fico bem quieta." 
O movimento de tentar encobrir a doença persistiu ao longo da intervenção quando, em vários momentos, precisei retomar os conteúdos relativos ao HIV conforme estavam previstos nos encontros. Ademais, ela pareceu ter deslocado muito dos sentimentos negativos trazidos pelo vírus para a relação com a sogra, que foi tornando-se mais conflituosa. A intervenção psicoeducativa breve impunha limites e foi difícil trabalhar essas resistências de Laura, que requeriam um enquadre de psicoterapia. Assim, busquei reforçar pontos positivos do enfrentamento do HIV, como a ênfase que conferia ao filho, além de escutar suas queixas e deixá-la falar da doença à vontade.

Apesar disso, Laura estava consciente da necessidade de manter o tratamento e agia de modo muito prático nesse sentido. No terceiro encontro, por exemplo, após esclarecer suas dúvidas com a fórmula láctea e o inibidor de lactação, as estratégias de sigilo quanto a não-amamentação que antecipou, confirmavam seu pragmatismo: "Vou dizer que o meu leite não desceu, que empedrou, é porque o meu seio tá enorme. [...] Ou digo que eu tive que tomar um remédio controlado mesmo. Logo que ele nasceu, que eu tive problema no parto."

Mesmo diante de resistências e dificuldades quanto ao diagnóstico, esperadas nos primeiros meses após essa notícia, foi possível identificar certo alívio emocional de Laura, evidenciado, por exemplo, na avaliação pós-intervenção: "[Os encontros] me esclareceram também muitas coisas na minha cabeça. De repente eu desabafava demais, contava. Acho que ela [terapeuta] sabe toda a minha vida que eu contei tudo para ela, isso ai é que é um alivio." Outro aspecto importante referiu-se à discussão das estratégias de sigilo quanto a não-amamentação no seio. Laura não pensara no assunto e pôde discutir alternativas, solicitando inclusive o apoio do marido sobre isso.

Apesar dos objetivos do PIP-Gestantes terem sido minimamente alcançados, a avaliação aos 3 meses do bebê revelou que as dificuldades emocionais de Laura persistiram e eram acompanhadas de sintomas psiquiátricos. Embora reconhecesse que seu estado emocional se assemelhava à sua reação inicial ao diagnóstico, Laura afirmava tranquilidade quanto à doença, pois seu estado de saúde era bom e não tinha problemas com os ARVs. Ao mesmo tempo, tentava localizar uma fonte para seus sintomas emocionais, situando-a na relação conflituosa com a sogra: "Meus exames tão bem, não penso mais nisso, nessas coisas de HIV. Eu não sei, de repente foi isso também que pode ter perturbado a minha cabeça, mas doutora, eu não penso outra coisa, a não ser naquela velha maldita!"

\section{Caso Miriam}

Miriam era dona de casa e esperava seu quarto filho. Seus três filhos eram frutos do primeiro casamento. Ela estava casada há três anos com seu segundo marido, cinco anos mais moço e sem filhos. Miriam soube do diagnóstico de HIV no início da gestação durante uma internação por grave anemia e ameaça de aborto. Após isso, ela perdeu a visão de um dos olhos por citomegalovirose e teve outra internação de um mês. Ela imaginava ter contraído o vírus de um namorado anterior ou então do marido atual, que tivera um relacionamento homossexual no passado, e não queria fazer o teste anti-HIV.

Até aquele momento, apenas o marido e uma irmã dela sabiam da doença e a apoiavam. A família morava próxima a Porto Alegre e buscaram atendimento na capital por não confiarem nos serviços de saúde locais. Miriam ia diariamente ao hospital para tratar a citomegalovirose e motivou-se a participar do estudo por ter preocupações e dúvidas sobre a profilaxia e o tratamento para HIV, sobre seu estado de saúde e do filho, relatando dificuldades para tomar os ARVs e sentindo-se irritada e estressada.

$\mathrm{Na}$ avaliação pré-intervenção, Miriam sabia do seu diagnóstico há apenas dois meses e, obviamente, estava sob o forte impacto da notícia, que se somava ao seu estado de saúde crítico. As exigências da profilaxia da TMI e do tratamento para a citomegalovirose em conjunto, adicionavam sobrecargas emocionais importantes e seu sofrimento era evidente, como ilustra seu relato: "Os médicos dizem: 'Não, é uma vida normal'. Só que não é uma vida normal! Porque tu tens que te cuidar muito mais para não ficar doente." O problema era pouco debatido entre o casal e a resistência do marido ao teste a afligia bastante. Ademais, a infecção pelo HIV era vista por Miriam não só como uma real ameaça a sua vida, mas também às relações interpessoais pelo risco do preconceito. Nos seus relatos, percebia-se que a doença era comum em seu meio social, fazendo-a temer que a não-amamentação denunciasse sua condição: "Todo mundo sabe, é uma doença que é espalhada pelo mundo todo. As pessoas no hospital já sabem que como não pode dar mamá, é porque tem algum problema!"

Miriam tinha nos filhos os motivos para viver e seguir o tratamento, tentando sufocar seus sentimentos quanto à doença. Destacava o apoio da irmã, do marido e da equipe de saúde que a acolheram de modo positivo, como disse antes da intervenção: "Na hora eu queria morrer! Depois não, agora até estou mais calma, porque eu olho os meus filhos. [Chora]. Mas não é fácil. Ainda bem que eu estou fazendo aqui [o tratamento], porque as pessoas são muito legais."

Ao longo da intervenção, Miriam recontou diversas vezes os fatos que envolveram seu diagnóstico, na busca por uma reestruturação interna e incorporação desses aspectos em sua autoimagem. Suas vivências, em particular com mães vivendo com o HIV, serviam para balizar aspectos de sua própria experiência e para dar-lhe outras perspectivas sobre o estigma e o enfrentamento da doença. Assim, a participação na intervenção pode ter facilitado um maior ajuste emocional frente à doença, ajudando-a a expressar seus sentimentos e angústias e a estabelecer suas atitudes diante disso. No segundo encontro, Miriam demarcou sua atitude positiva e de superação diante da aids, o que também explicitou em outros momentos.

Miriam: Eu tive uma amiga que morreu há anos. [...] Ela morreu bem nova também. Só que eu não sabia o que que era isso. Só que agora como eu já sei mais ou menos como é, ela morreu de aids. [...] E ela ficou cega. [...] Eu me lembrei dela, porque ela não quis mais viver. [...]

Terapeuta: E o quê que tu ficaste pensando, como é que tu te sentiste? 
Miriam: Eu acho que me deu mais reação. [...] Eu disse: "Não, eu quero viver!" [ri] E eu quero mesmo, sabe?

Com o passar dos encontros, ela referiu estar mais tranquila e sua narrativa sobre o diagnóstico, inicialmente confusa, foi ficando mais clara:

Eu já estava grávida e quando eu fui fazer aqueles exames de rotina, a minha anemia. Eu comecei a desmaiar, a ficar tonta, fraca, foi quando eu baixei o hospital. [...] Eu comecei a ver, acho que eu estou com glaucoma nas vistas! [...] Quando eu vim no posto a doutora disse: "Não, pode pegar esse papel de alto risco! Porque os teus exames tão horríveis!" Só que eu não tinha feito o do HIV.

No contato com outras pessoas com HIV, passou a mostrar maior naturalidade em lidar publicamente com a doença, legitimando sua escolha pelo sigilo com os familiares. Ver que outros viviam problemas como os seus fornecia um sentido de normalização diante da doença.

Discutimos ainda estratégias para manter o sigilo quanto a não-amamentação e de recorrer ao apoio da irmã e do marido nessas situações. Contudo, ela ainda se sentia desconfortável e entristecida por não poder dar o seio ao filho. Outro ponto de destaque é que o casal passou a conversar mais sobre a doença em função da participação de Miriam na intervenção. Os relatos revelaram que o casal discutia os assuntos dos encontros e que ela passou a defender que a realização do teste anti-HIV pelo marido traria benefícios para ambos, como mencionado no quinto encontro: "Nós conversamos: 'Eu vou falar com a L. [enfermeira] e dai amanhã ele vai vim comigo para fazer os exames. [...] Eu já estava agoniada. Não pode deixar. Dai dois doentes?"

Após o nascimento, o filho se tornou o centro de suas estratégias para lidar com a doença. Aos 3 meses do bebê, Miriam referiu não ter tido problema para manter o sigilo frente a não-amamentação e relatou ter revelado o diagnóstico para seu pai. Sobre isso, uma maior assimilação do diagnóstico e do tratamento talvez tenha facilitado essa revelação, que tanto alívio lhe trouxe. O diagnóstico de HIV na gestação foi muito penoso para Miriam que lidava com vários problemas de saúde e o risco da TMI, envolvendo, portanto, uma grande carga de culpa e incerteza sobre a saúde do bebê. Parece ter sido possível para ela falar ao pai sobre a doença depois da certeza de que o filho estava fora de risco, tendo sido fundamental o apoio da equipe de saúde na manutenção do segredo: "As pessoas foram muito queridas para mim quando eu fiquei baixada no hospital. Eles faziam assim, para não contar, porque ele [pai] é uma pessoa de idade e se tiver que contar, eu quero contar." Apesar da insistência dela, o marido resistia em fazer o exame anti-HIV e novo encaminhamento foi realizado.

\section{Discussão}

O presente estudo investigou as contribuições de uma intervenção psicoeducativa durante a gestação para enfrentamento do HIV. Ficou patente a complexidade e intensidade dos sentimentos envolvendo a maternidade nesse contexto, cercado de tantos cuidados, do temor de infectar o filho e da ameaça trazida pela revelação do diagnóstico. A notícia do HIV durante a gravidez mostrou representar grande risco psicológico, já que o esforço de adaptação e a sobrecarga emocional eram potencializadas por envolverem o filho. Com isso, identificaram-se contribuições de uma intervenção psicoeducativa breve para as gestantes. Particularmente, o apoio emocional e informativo promovido pela intervenção parece ter favorecido um enfrentamento mais ativo das mães diante do HIV, reforçando achados quanto ao PIP-Gestantes (Carvalho, 2009) e de outras intervenções nesse contexto (Jirapaet, 2000; Miles et al., 2003).

Foi possível abordar com as mães, de modo personalizado, pontos críticos da profilaxia da TMI, antecipando dificuldades quanto à preservação do sigilo, por exemplo. Discutir estratégias de sigilo parece ter possibilitado uma preparação para lidar com desconfianças relativas a não-amamentação, em especial para três das mães. Acredita-se que a participação no PIP-Gestantes tenha contribuído para uma maior adaptação à doença, pois as mães relataram alívio emocional e mais segurança na relação com o HIV e a profilaxia. Consoante à literatura, um bom ajustamento ao HIV implicaria na aquisição de um senso de controle sobre a doença, estimulando atitudes ativas frente ao tratamento (Swendeman, Ingram, \& Rotheram-Borus, 2009).

Mesmo não pretendendo aprofundar aspectos subjetivos, as análises indicaram que a intervenção facilitou a reflexão e um reposicionamento das mães frente ao HIV, por meio da acolhida e escuta dos seus temores. Obviamente, as mudanças verificadas ao longo da intervenção foram facilitadas pelo apoio por parte dos familiares e da equipe de saúde (Pereira $\&$ Canavarro, 2009). Ao mesmo tempo, pode-se pensar que atender às demandas emocionais e informativas das gestantes tenha tido importante função ao preencher lacunas do serviço de saúde (falta de psicólogo), e fragilidades na rede de apoio familiar. Embora três maridos não tenham participado, os relatos de duas mães mostraram que eles estavam atentos à intervenção, o que pode ter auxiliado a fomentar a discussão dos temas pelo casal.

Apesar dos aspectos positivos, identificaram-se algumas limitações da intervenção em atender às demandas das mães vivendo com HIV. A brevidade e o caráter focal não oportunizou abordar aspectos mais profundos e conflituosos quanto ao diagnóstico. Como revelado por dois casos, a notícia do HIV na gravidez parece amplificar riscos psicológicos preexistentes, além de instaurar um período de crise emocional e familiar que continua repercutindo após o parto (Kwalombota, 2002; Sanders, 2008). O estudo de Carvalho (2009) apontou que o impacto positivo do PIPGestantes para o enfrentamento e a qualidade de vida das mães era maior quanto maior o tempo de diagnóstico, não tendo sido incluídas mães com diagnóstico na gravidez. Os achados deste estudo indicaram que apesar das contribuições da intervenção às gestantes com diagnóstico recente, estas precisam ser acompanhadas após o parto visando a amparar a adaptação à doença e, assim, protegendo o desenvolvimento emocional da criança.

O presente estudo evidenciou ainda aspectos relativos à convivência com o vírus e ao atendimento de gestantes e mães vivendo com o HIV. O estigma e o preconceito associados 
à doença ainda permanecem impondo sentimentos íntimos muito negativos e restrições nas relações interpessoais (Santos, França, \& Lopes, 2007). Os relatos das mães do presente estudo revelaram que a demanda pela manutenção de sigilo, especialmente em situações envolvendo a maternidade, é muito presente e precisa ser respaldada pelos profissionais de saúde no sentido de garantir a elas esse direito. Um dos casos foi emblemático nesse sentido, pois, apesar do esforço e da afirmação explícita de que não desejavam revelar a doença para a família, houve a quebra de sigilo. A quebra do sigilo no contexto da gestação, parto ou primeiros meses do bebê pode ser bastante penalizante para as famílias em um momento que envolve intensa culpa e incerteza quanto à TMI (Varga, Sherman, \& Jones, 2006), abrindo margem para julgamento moral e mais desgaste emocional.

Por outro lado, poucas situações de discriminação foram relatadas pelas mães e, em geral, a revelação do diagnóstico resultou em reações de apoio que, conforme a literatura, facilitam o ajustamento à gestação e à doença (Pereira \& Canavarro, 2009). Assim, considera-se que a revelação pode ter um impacto positivo, ao consolidar relações de apoio e intimidade, e as mães deveriam ser auxiliadas, caso desejem, a contar aos familiares de sua escolha. Já a não-amamentação no seio trouxe sentimentos muito penosos para as gestantes que desafiavam íntima e socialmente seu status materno, endossando outro estudo (Moreno, Rea, \& Filipe, 2006). Como se viu, o HIV é tão presente em alguns meios sociais que a não-amamentação tende a ser facilmente associada à doença, aumentando a vulnerabilidade dessas mulheres (Varga et al., 2006).

Outro aspecto destacado na literatura é a importância de uma postura empática e apoiadora dos profissionais de saúde para o ajustamento psicológico dos pacientes vivendo com HIV (Fehringer et al., 2006; Sanders, 2008). Nesse sentido, os relatos das mães do presente estudo revelaram tanto aspectos positivos quanto negativos. Por um lado, a acolhida e a confiança na equipe de profissionais facilitaram, em várias situações, o tratamento de saúde e a expressão de sentimentos, o que contribuía para um maior senso de controle sobre a doença. Ao mesmo tempo, evidenciaram-se fragilidades em especial quanto ao sigilo e a atenção aos direitos reprodutivos. Desse modo, reforça-se a necessidade de uma atenção individualizada e sensível, com profissionais capacitados para identificar e intervir diante de riscos psicossociais, buscando a integralidade da atenção a pessoas vivendo com HIV (Carneiro \& Coelho Ede, 2010).

Ao final desse estudo, cabe pontuar algumas limitações. Embora não fosse o foco do estudo, a participação dos outros pais poderia ter contribuído no enfrentamento da doença pelas mães. Sugere-se que futuras pesquisas continuem incluindo os pais, promovendo sua participação nesse contexto. Outra limitação refere-se a não ter analisado o emprego do aconselhamento e do processo terapêutico enfocando as interações entre a terapeuta e as mães, o que auxiliaria a aprimorar a intervenção. Ainda, mesmo baseado em extenso material e análises detalhadas, o estudo limitou-se a quatro casos e outras mães podem ter experiências distintas.

\section{Considerações Finais}

O presente estudo evidenciou que essas mães lidam com uma doença crônica e estigmatizante que traz diversos desafios e é nesse contexto que muitas engravidam e precisam criar os filhos, condições estas muitas vezes agravadas por dificuldades socioeconômicas. Defende-se que as políticas públicas não devem centrar-se apenas na redução das taxas de TMI, o que certamente é essencial, mas também em ações que criem condições materiais, de saúde física e mental para o exercício da maternidade e ao melhor interesse da primeira infância. É inadmissível que ocorram situações de sofrimento e desatenção a essas mães, fruto do despreparo de alguns profissionais. Em um cenário de tantas dificuldades e mesmo com limitações, a intervenção psicoeducativa teve contribuições importantes no que se refere ao enfrentamento do HIV. Essas evidências sublinham ser fundamental a atenção psicológica e o apoio atento dos serviços de saúde a essas mulheres para que exerçam seu direito à maternidade de modo menos sofrido, garantindo o desenvolvimento emocional dos seus filhos e a sua presença na vida deles.

\section{Referências}

Brasil/MS, Ministério da Saúde (1999). Aconselhamento: um desafio para prática integral em saúde. Brasília: Ministério da Saúde. Coordenação Nacional de DST/Aids.

Brasil/MS, Ministério da Saúde (2005). Oficina de Aconselhamento em DST/HIV/Aids para a atenção Básica. Brasília: Ministério da Saúde. Programa Nacional de DST/Aids.

Brasil/MS, Ministério da Saúde (2011). Boletim Epidemiológico Aids-DST- $n^{o}$ VI, $26^{a}$ a $52^{a}$ semanas epidemiológicas, julho a dezembro de 2010 e $01^{a}$ a $26^{a}$ semanas epidemiológicas, janeiro a junho de 2011. Brasília: Ministério da Saúde, Departamento de DST, Aids e Hepatites Virais.

Brasil/MS, Ministério de Saúde (2010). Recomendações para profilaxia da transmissão vertical do HIV e terapia antirretroviral em gestantes - Versão Preliminar. Brasília: Ministério da Saúde, Departamento de DST, Aids e Hepatites Virais.

Carneiro, A. J., \& Coelho Ede, A. (2010). Aconselhamento na testagem anti-HIV no ciclo gravídico-puerperal: o olhar da integralidade. Ciência e Saúde Coletiva, 15(Suppl 1), 12161226.

Carvalho, F. T. (2009). Contribuições de uma intervenção psicoeducativa para estratégias de enfrentamento e qualidade de vida de gestantes portadoras de HIV/Aids. (Unpublished doctoral dissertation). Universidade Federal do Rio Grande do Sul, Porto Alegre.

Carvalho, F. T., Faria, E. R., Gonçalves, T. R., Moskovics, J., M., \& Piccinini, C. A. (2009). Intervenção psicoeducativa para gestantes vivendo com HIV/Aids: um revisão de literatura. Psicologia: Teoria e Prática, 11(3), 157-173.

Faria, E. R., Gonçalves, T. R., Carvalho, F. C., Moskovics, J., \& Piccinini, C. A. (2012). Intervenções psicológicas para portadores do HIV/Aids: modelos, resultados e lacunas. Interamerican Journal of Psychology, 45(1), 339-350.

Faria, E. R., \& Piccinini, C. A. (2010). Maternidade no contexto do HIV/Aids: Gestação e terceiro mês de vida do bebê. Estudos de Psicologia (Campinas), 27(2), 145-159. 
Fehringer, J., Bastos, F. I., Massard, E., Maia, L., Pilotto, J. H., \& Kerrigan, D. (2006). Supporting adherence to highly active antiretroviral therapy and protected sex among people living with HIV/AIDS: the role of patient-provider communication in Rio de Janeiro, Brazil. Aids Patient Care and STDS, 20(9), 637-648.

Gerbert, B., Danley, D.W., Herzig, K., Clanon, K., Ciccarone, D., Gilbert, P., \& Allerton, M. (2006). Reframing "prevention with positives": incorporating counseling techniques that improve the health of HIV-positive patients. Aids Patient Care and STDS, 20(1), 19-29.

Gonçalves, T. R. (2011). Maternidade e HIV/Aids no contexto de uma intervenção psicoeducativa durante a gestação. (Unpublished doctoral dissertation). Universidade Federal do Rio Grande do Sul, Porto Alegre.

Gonçalves, T. R., \& Piccinini, C. A. (2008). Experiência da maternidade no contexto do HIV/Aids aos três meses de vida do bebê. Psicologia: Teoria e Pesquisa, 24(4), 459-470.

Jirapaet, V. (2000). Effects of an empowerment program on coping, quality of life, and the maternal role adaptation of Thai HIVinfected mothers. Journal of the Association of Nurses in AIDS Care, 11(4), 34-45.

Joffe, H., \& Yardley, L. (2004). Content and thematic analysis. In D. F. Marks \& L. Yardley (Eds.), Research methods for clinical and health psychology (pp. 56-68). London: SAGE.

Kwalombota, M. (2002). The effect of pregnancy in HIV-infected women. Aids Care, 14(3), 431-433.

Laville, C., \& Dione, J. (1999). A construção do saber. Porto Alegre: Artmed.

Medley, A., Garcia-Moreno, C., McGill, S., \& Maman, S. (2004). Rates, barriers and outcomes of HIV serostatus disclosure among women in developing countries: implications for prevention of mother-to-child transmission programmes. Bulletin of the World Health Organization, 82(4), 299-307.

Miles, M. S., Holditch-Davis, D., Eron, J., Black, B. P., Pedersen, C., \& Harris, D. A. (2003). An HIV self-care symptom management intervention for African American mothers. Nursing Research, 52(6), 350-360.

Moreno, C. C. G. S., Rea, M. F., \& Filipe, E. V. (2006). Mães HIV positivo e a não-amamentação. Revista Brasileira de Saúde Materno Infantil, 6(2), 199-208.
Pereira, M. \& Canavarro, M. C. (2009). Relational contexts in adjustment to pregnancy of HIV-positive women: relationships, social support and personal adjustment. AIDS Care-Psychological and Socio-Medical Aspects of Aids/Hiv, 21(3), 301-308.

Piccinini, C. A., Carvalho, F. T., Ramos, M. C., Gonçalves, T. R., Lopes, R. C. S., Hugo, C. N., et al. (2005). Aspectos psicossociais, adesão ao tratamento e saúde da mulher no contexto do HIV/AIDS: contribuições de um programa de intervenção da gestação ao segundo ano de vida do bebê. Porto Alegre: UFRGS. Unpublished research project, Universidade Federal do Rio Grande do Sul, Porto Alegre.

Sanders, L. B. (2008). Women's voices: the lived experience of pregnancy and motherhood after diagnosis with HIV. Journal of the Association of Nurses in AIDS Care, 19(1), 47-57.

Santos, E. C., França, I., \& Lopes, F. (2007). Qualidade de vida de pessoas vivendo com HIV/Aids em São Paulo. Revista de Saude Publica, 41(Suppl 2), 64-71.

Souza Jr, P. R., Szwarcwald, C. L., Barbosa Jr, A., Carvalho, M. F., \& Castilho, E. A. (2004). Infecção pelo HIV durante a gestação: estudo-Sentinela Parturiente, Brasil, 2002. Revista de Saúde Pública, 38(6), 764-772.

Stake, R. E. (1994). Case studies. In N. Denzin \& Y. Wilson (Eds.), Handbook of Qualitative Research (pp. 236-247). London: Sage.

Stern, D. N. (1997). A constelação da maternidade. Porto Alegre: Artes Médicas.

Swendeman, D., Ingram, B., \& Rotheram-Borus, M. (2009). Common elements in self-management of HIV and other chronic illnesses: an integrative framework. AIDS Care, 21(10), 1321-1334.

Varga, C. A., Sherman, G. G., \& Jones, S. A. (2006). HIV-disclosure in the context of vertical transmission: HIV-positive mothers in Johannesburg, South Africa. AIDS Care, 18(8), 952-960.

Wilson, S. (2007). 'When you have children, you're obliged to live': motherhood, chronic illness and biographical disruption. Sociology of Health and Illness, 29(4), 610-626.

Recebido em 26.04.2013

Primeira decisão editorial em 29.04.2013

Versão final em 04.11.2014

Aceito em 04.11.2014 